\title{
Personal Learning Environments (PLEs): Visions and Concepts
}

\author{
Alexander Mikroyannidis, Sylvana Kroop, and Martin Wolpers
}

\begin{abstract}
Personal learning environments (PLEs) hold the potential to address the needs of formal and informal learners for multi-sourced content and easily customisable learning environments. This chapter presents an overview of the European project ROLE (Responsive Open Learning Environments), which specialises in the development and evaluation of learning environments that can be personalised by individual learners according to their particular needs, thus enabling them to become self-regulated learners.
\end{abstract}

Keywords Personal learning environment • Self-regulated learning • Responsive open learning environment

\section{Introduction}

An ageing society and a flexible economy need lifelong learning more than ever, otherwise risking that school kids today know more than employees trained half a decade ago. Lifelong learning requires learners to actively control their learning activities while addressing the requirements imposed on them in their respective life contexts. Life context here can be the school, the university, the workplace, the hobby, etc. This leads to a shift from a centralised institutional teaching approach to a more learner-centred decentralised learning approach (Wilson 2005). In order to support this shift, learning environments must change to be more responsive and open, allowing effectively addressing individual needs of learners and teachers.

\footnotetext{
A. Mikroyannidis $(\bowtie)$

Knowledge Media Institute, The Open University, Milton Keynes MK7 6AA, UK

e-mail: a.mikroyannidis@open.ac.uk

S. Kroop

Zentrum for Social Innovation, Vienna, Austria

e-mail: kroop@zsi.at

M. Wolpers

Fraunhofer FIT, Schloss Birlinghoven, Sankt Augustin, Germany 53754

e-mail: martin.wolpers@fit.fraunhofer.de 
In this chapter, we will reflect on the approach of the European project ROLE (Responsive Open Learning Environments ${ }^{1}$ ). ROLE enables learners individually to compile their personal learning environments (PLEs) according to their particular needs and goals. Consequently, the ROLE approach supports self-regulated learning (SRL) while taking into account the requirements from the roles of the learners and the teachers.

The remainder of this chapter is structured as follows: Recent advances in personalised and SRL are introduced. Subsequently, the widget-based approach of the PLE is presented, along with the process of building a PLE using widgets. This is followed by an introduction to the ROLE project and its key innovations, with particular emphasis on evaluating these innovations via a number of case studies and test beds. An example of a recent research initiative that builds upon the results of the ROLE project is provided in the section that presents the weSPOT project. Finally, the chapter is concluded with a summary of the key ROLE contributions to technology-enhanced learning and an overview of what is presented by each chapter in the rest of this book.

\section{Personalised and Self-Regulated Learning}

The Learning Management System (LMS) has dominated technology-enhanced learning for several years. It has been widely used by academic institutions for delivering their distance learning programmes, as well as for supporting their students outside the classroom. The LMS has been a powerful tool in the hands of educators, enabling them to complement face-to-face teaching in the classroom with remote work by individual students, as well as groups of them (Bri et al. 2009; Wainwright et al. 2007; Abel 2006; Watson et al. 2007).

However, the advent of Web 2.0 has altered the landscape in technologyenhanced learning. Learners nowadays have access to a variety of learning tools and services on the cloud. These tools and services are usually provided by different vendors and in many cases are open and free. However, augmenting and configuring these diverse and distributed tools and services in order to address the needs and preferences of individual learners is a significant challenge for modern online learning environments.

This ongoing transition from the traditional approach of the LMS towards Web 2.0-based learning solutions bears significant benefits for learners. It puts emphasis on their needs and preferences, providing them with a wider choice of learning resources to choose from. Learners usually switch learning contexts continuously, adapting to the respective needs automatically. The LMS is not able to provide learners with the required flexibility. Furthermore, the LMS is a closed system that does not allow the learner to take her achievements with her when changing the

\footnotetext{
${ }^{1}$ http://www.role-project.eu
} 
LMS-providing learning organisation, e.g. while starting a new job, the previously used LMS-profile cannot easily be transferred to the new one used at the workplace.

The PLE is a facility for an individual to access, aggregate, manipulate, and share digital artefacts of their ongoing learning experiences. The PLE follows a learner-centric approach, allowing the use of lightweight services and tools that belong to and are controlled by individual learners. Rather than integrating different services into a centralised system, the PLE provides learners with a variety of services and hands over control to them to select and use these services the way they deem fit (Chatti et al. 2007; Wilson 2008).

The emergence of the PLE has greatly facilitated the use and sharing of open and reusable learning resources online. Learners can access, download, remix, and republish a wide variety of learning materials through open services provided on the cloud. Open Educational Resources (OER) can be described as "teaching, learning and research resources that reside in the public domain or have been released under an intellectual property license that permits their free use or repurposing by others depending on which Creative Commons license is used" (Atkins et al. 2007).

SRL comprises an essential aspect of the PLE, as it enables learners to become "metacognitively, motivationally, and behaviourally active participants in their own learning process" (Zimmerman 1989). Although the psycho-pedagogical theories around SRL predate very much the advent of the PLE, SRL is a core characteristic of the latter. SRL is enabled within the PLE through the learnerdriven assembly of independent resources in a way that fulfils a specific learning goal. By following this paradigm, the PLE allows learners to regulate their own learning, thus greatly enhancing their learning outcomes (Steffens 2006; Fruhmann et al. 2010).

\section{The Widget-Based Approach of the PLE}

As online learners become more discerning in terms of the choices related to the types and styles of their potential study materials, they will potentially seek content from multiple sources. In addition, because of the flexibility and ease of use that enables many users to customise that content, those same learners may wish to personalise their learning environment.

The PLEs presented in this book are primarily enabled by widgets, which are micro-applications performing a dedicated task. This task can be as simple as showing news headlines or weather forecasts, but also more complex like facilitating language learning or collaborative authoring. Widgets can be either desktop based or web based. Desktop-based widgets reside locally on your computer and may access the web for information, such as a desktop widget that shows the local temperature and weather. Web-based widgets reside on the web and can be embedded on a web page, such as an RSS reader widget that fetches news on your start 


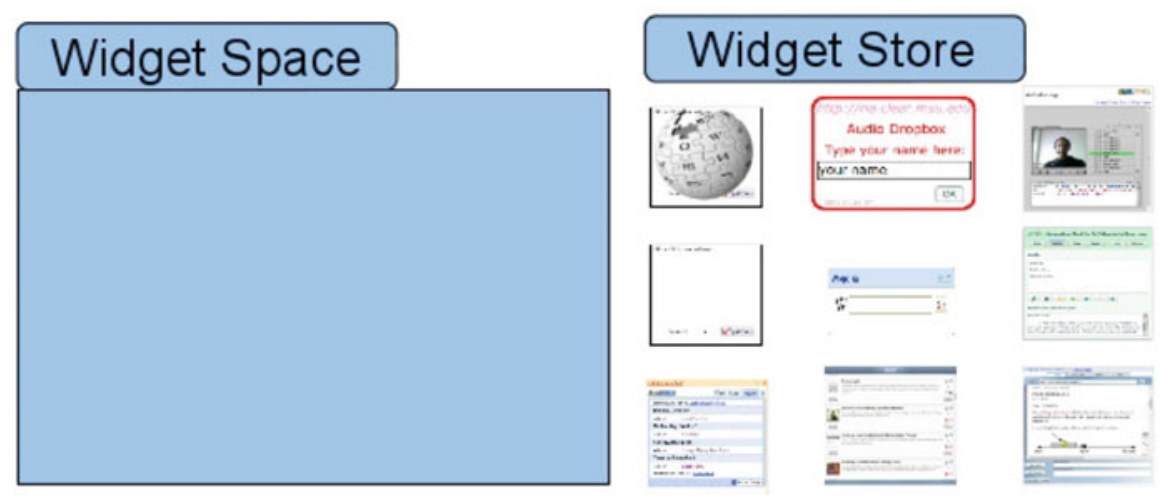

Fig. 1 Browser- and widget-based PLE concept

page. Web-based widgets have proven quite popular as they enhance the interactivity and personalisation of web sites.

As already mentioned above, the theoretical idea of PLEs is not a specific software application. A PLE is instead a concept based on the idea to have learner-centric Web 2.0-based environments individually designed. It is not a one-size-fits-all learning environment but a personalised environment a learner takes control over his/her own learning process instead of being controlled by a pre-delivered orchestration of learning goals, tools, services, and content. In PLE research it is deemed essential to have a learner challenged by offering her the ability to create her individually controlled and preferred learning environment.

In the ROLE project, the basic equipment for creating PLEs has been developed according to the idea of an easy drag-and-drop system of widgets.

On the one hand, a repository (widget store) is necessary to store and administrate useful widgets. On the other hand an enabler space (widget space) is necessary to have learners their individually preferred widgets integrated, used, and managed in their personal style. Figure 1 outlines this approach schematically.

From a user perspective, ROLE is Software as a Service (SaaS) (Mell and Grance 2011; Vaquero et al. 2008) — the user does not install and run it locally. This paradigm affects three main aspects of the user-visible parts of ROLE:

- Widget space: The widget space contains a number of personally selected learning widgets whereby all of them access and use already existing and established external OER. It is the virtual environment where the user installs and uses its widgets.

- Single widget: A single widget abstracts (accesses and uses) at least one single external resource. There are widgets accessing and using just one single external resource, e.g. a Wikipedia widget or an LEO dictionary widget. Furthermore, some widgets have been implemented to make use of cloud computing to an extensive degree. One example is the "ROLE translator widget" which accesses and displays the results of different popular resources such as LEO.org, dict.cc, 
Wikipedia, and Google translator. The results of translating a specific term are used from all translating resources at the same time and are displayed in the same place by using the ROLE translator widget. Thus a learner has a better and more critical overview by being able to quickly compare the provided Web 2.0-based translation data. One more interesting example of a cloud computing-based widget is "Binocs" which displays search results by using different external resources and depending on the used resources of a personal network of trusted friends, colleagues, and experts (Govaerts et al. 2011). All widgets can be found in the ROLE Widget Store described in the following section.

- Multiple devices: ROLE widgets and content can be accessed and used with different devices. Depending on the widgets and content, it can be used by all kind of browser-based applications on notebooks, smartphones, tablets, etc.

\section{Building a Widget-Based PLE}

In order to build a widget-based PLE, the learner will need to access a widget store. A widget store is a directory of widgets, where widgets are commonly categorised according to their purpose, e.g. widgets for planning, communication, and collaboration. An example of such a categorisation is shown in Fig. 2. The learner can browse and download the widgets, as well as provide feedback on them in the form of ratings and comments. The ROLE project has built a widget store dedicated to widgets for learning purposes. ${ }^{2}$

After selecting the appropriate widgets, the learner needs to add them to the web space of their choice and start using them for their learning, either by themselves or in collaboration with other learners. Widgets can also be embedded inside an LMS, such as Moodle, thus enhancing its functionality and content, as shown in Fig. 3. Additionally, ROLE offers a facility for creating a shared learning space and populating it with widgets. ${ }^{3}$

For more information on building a PLE and using it to become a self-regulated learner, one can refer to the following free online courses that have been developed by ROLE:

- Responsive open learning environments ${ }^{4}$ : This course provides an overview of the concepts behind PLEs and also demonstrates a selection of ROLE widgets within learning activities. Figure 4 shows such an activity, where the learner is invited to use a ROLE widget in order to complete a series of learning tasks.

\footnotetext{
${ }^{2}$ http://www.role-widgetstore.eu

${ }^{3} \mathrm{http}: / /$ role-sandbox.eu

${ }^{4}$ http://labspace.open.ac.uk/course/view.php?id=7433
} 


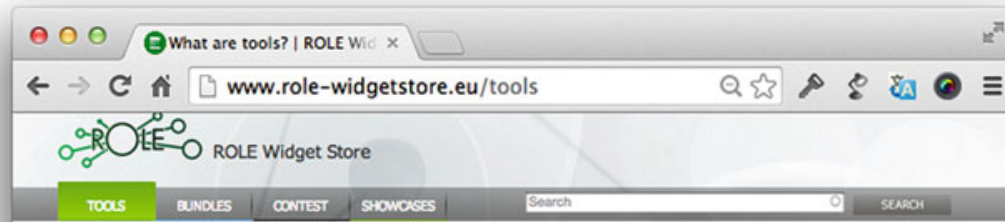

\section{WHAT ARE TOOLS?}

Tooks, or widgets, are smal web based software appications supporting specife leaming or teaching gools and tasks. Widgets can be added to a Personal

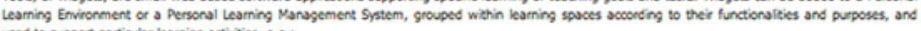
used to sapport porticular learning activites, e.g:

$\longrightarrow$ Daming and coganization of learning processes

- seanch for kearning content (teats, presentations, videos, etc)

$\rightarrow$ realtime learner communication and colaboration

- recommencation (learning content, peers, tools, etc)

- reflection and evolwtion processes

- training and testing activies (e.g. Vocabulary Trainer)

- ceation and manipulation of learning content

- pedagogical processes (c.g. task and activity trading)

\section{Add a new tool}

Here you can add a new tool to the Wdget Store. The Wdget Store supports OpenSodial and W3C widget specifations. To submit a tool you must have been registered at the store. You can $9 e t$ an account here, You can also add topls without being the auther, 7 this is allowed by the given licence. Ater you submitted at tool a member of the ROL consortium will review pur tool and echer publish it er contact you because of possble improvement. You can see the status of the tool at the My Content page.

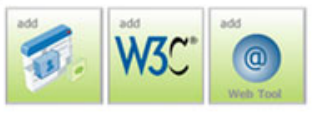

Tool categories
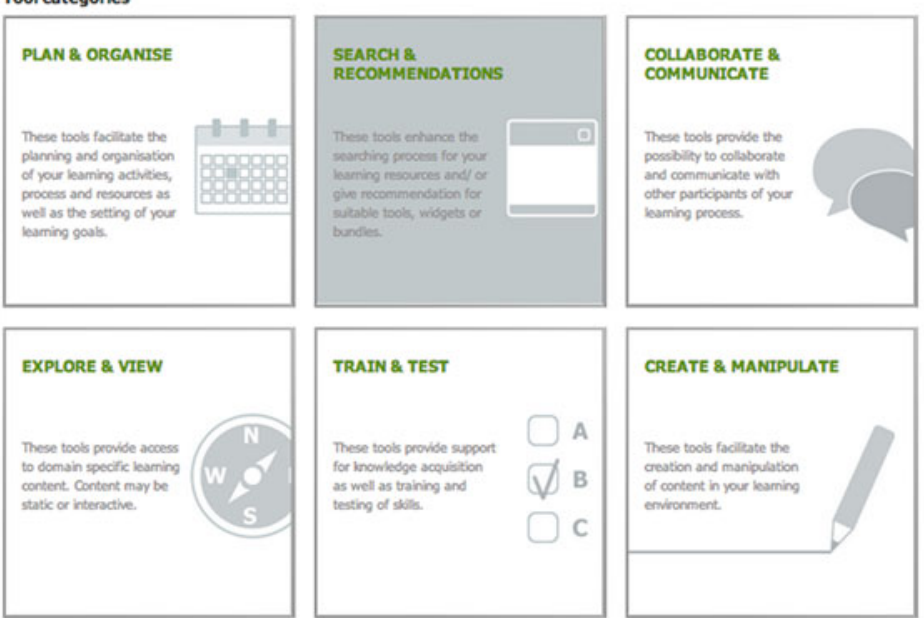

CREATE \& MANIPULATE
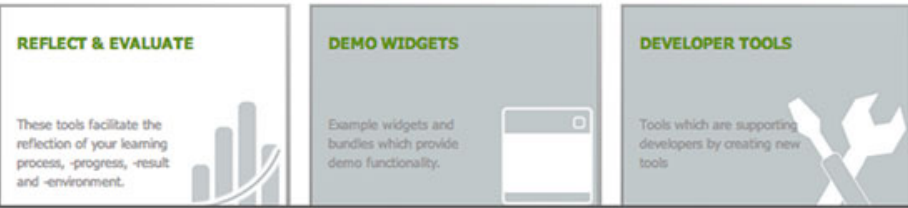

Fig. 2 The ROLE widget store offers widgets (tools) for a variety of learning purposes, categorised according to learning tasks 


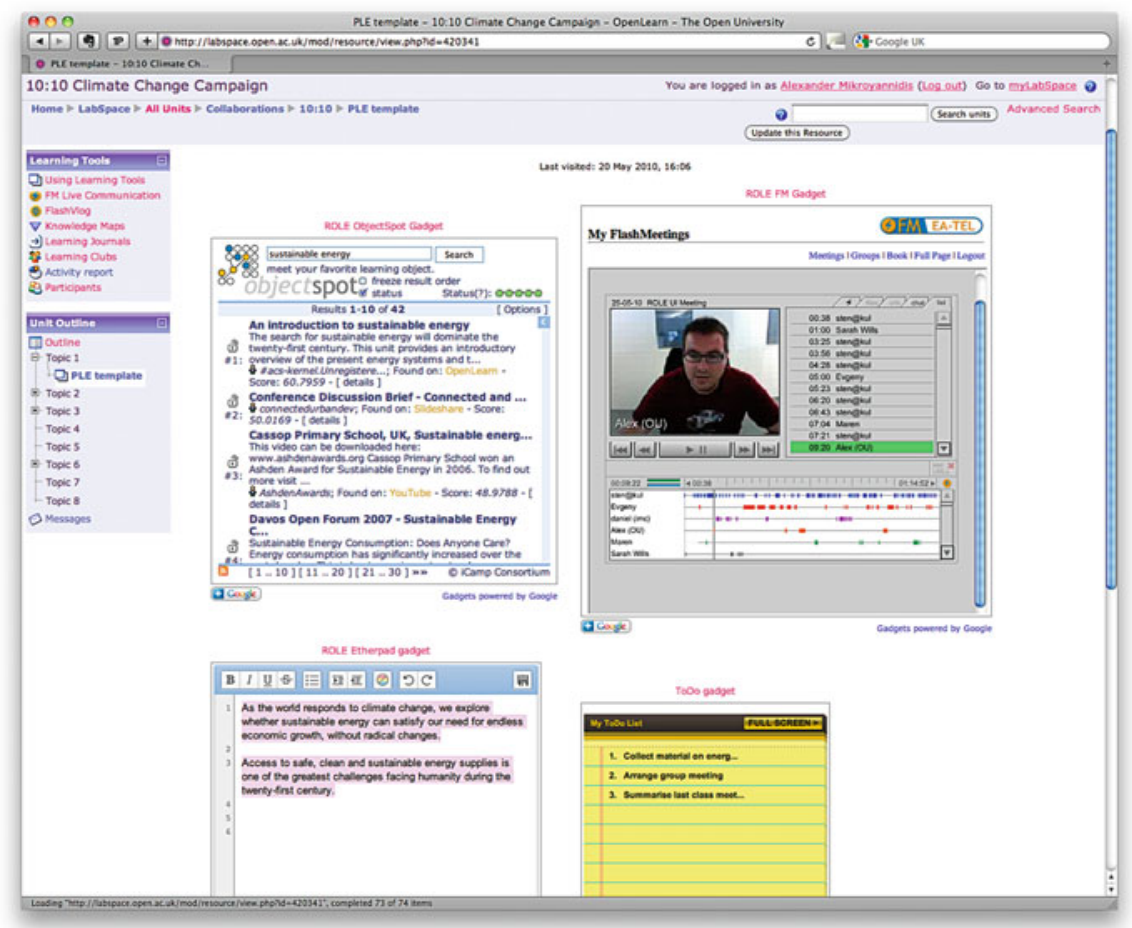

Fig. 3 ROLE widgets embedded inside a Moodle course. The learner uses them to search for learning resources, as well as collaborate with other learners through videoconferencing and a shared writing pad

- Self Regulated Learning ${ }^{5}$ : This course introduces the concept of SRL and guides learners into using the ROLE tools in order to apply the SRL principles into their own learning.

The content of these two courses is also available as a free interactive eBook, developed for the iPad and MacOS (Mikroyannidis et al. 2013a). The eBook provides an introduction to the new learning technologies that empower SRL and PLEs. A selection of widgets that will help readers build their own PLE and become a self-regulated learner are also demonstrated. Readers have an opportunity to interact with these widgets through a set of learning activities included in the eBook.

\footnotetext{
${ }^{5}$ http://labspace.open.ac.uk/course/view.php?id=7898
} 


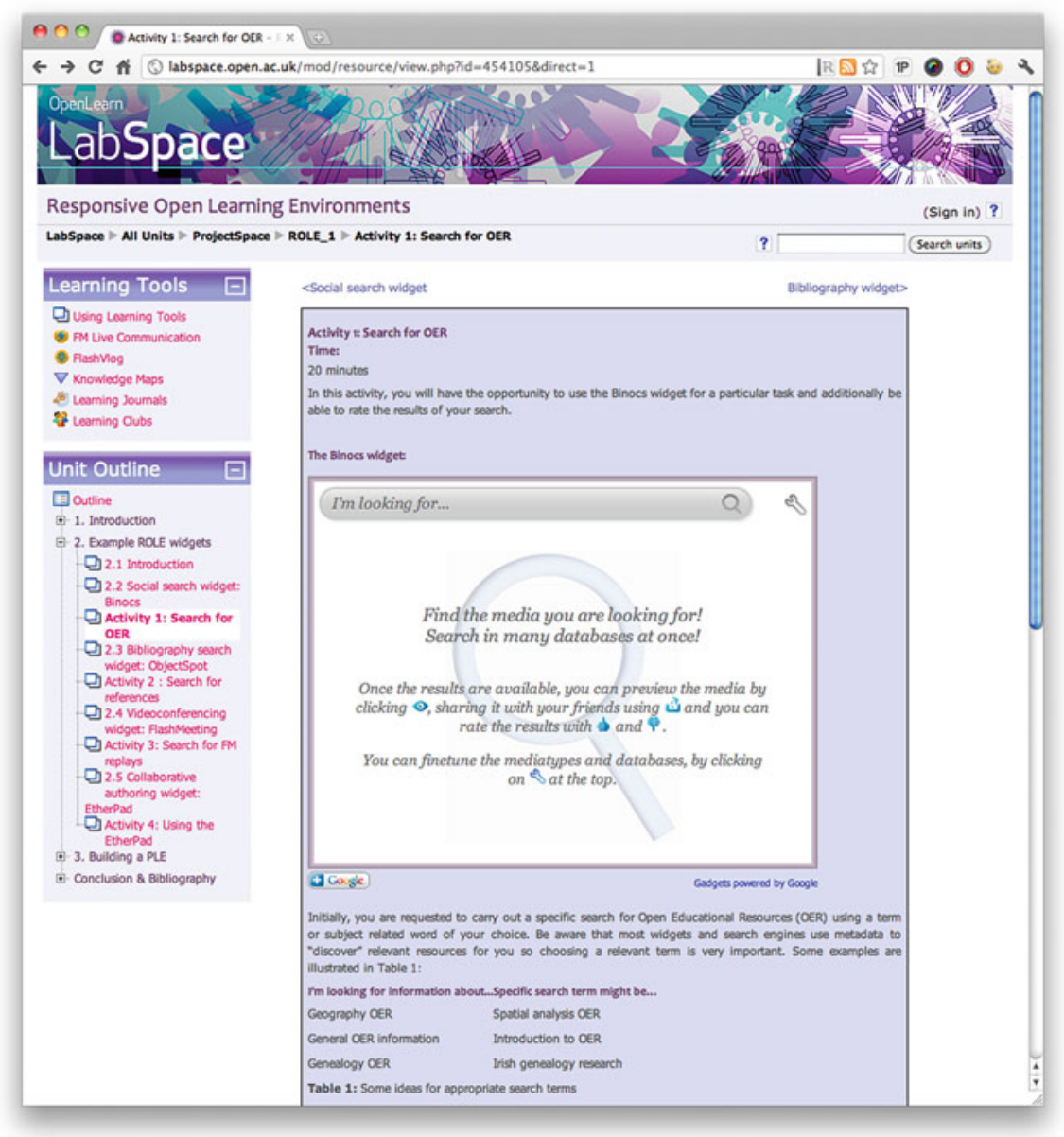

Fig. 4 A learning activity of a free online course developed by ROLE, featuring a search widget and a step-by-step guide on completing a series of learning tasks

\section{The ROLE Project and Its Key Innovations}

ROLE is a European-funded initiative with 16 internationally renowned research groups from six European countries and China. It started on February 2009 with a duration of 4 years. ROLE was established to research and explore a variety of tools and services that enable learners to build their PLE, based on their needs and preferences. ROLE has brought forward the innovations in PLEs and SRL, through research in the following directions:

- User-centric approach to learning environments with a focus on end-user development to design and control a PLE. 
- Contemporary pedagogical models for personalisation in learning networks, SRL and collaboration in networked communities.

- Contemporary engineering frameworks for designing, integrating, orchestrating, and evaluating learning services, tools, and content.

- Frameworks for evaluating learner interactions in learning networks.

The notion of lifelong learning as discussed today formulates a number of requirements on the technological basis as well as the associated learning and business/organisational processes. As our target group ranges from all possible domains and roles, e.g. learners, teachers, companies, employer, employees, and learning organisations, opportunities arise that will support the current shift in education towards more self-regulated learners (Van Harleman 2006) in scenarios, where the teacher role shifts more towards a mentoring role: the centralised institutional teaching approach shifts to a more learner-centred decentralised learning approach (Wilson 2005).

The ROLE project provides solutions to this set of complex challenges by advancing the state of the art in the technology and methodology. The following sections outline the ROLE approach in technology and methodology.

Technology: interoperable infrastructure enables PLE composition-ROLE has provided an infrastructure that enables learners to create their own PLEs, while maintaining a close link to the rules and restrictions of the education-providing organisation (Isaksson 2013; Dahrendorf 2013). In essence, the idea is to loosen the control on the learner while maintaining the ability to certify learner achievements. For example, the learner chooses the required learning tools and contents from a wide selection and compiles them into her individual PLE. At the same time, the education provider can control which tools and contents can be chosen by the learner.

ROLE tools and content within the PLE are able to communicate with each other in order to enable tools and contents to react to each other based on the user interaction. Finally, rather than replacing LMS, the ROLE approach allows the successful augmentation of existing learning environments. This way, the costs for introducing the ROLE approach to existing learning environments is significantly reduced, which fosters its uptake.

Methodology: self-regulation as the key learning paradigm-Learners today are not aware of the advanced learning paradigm of SRL. In most cases, the basic components of SRL, that is, cognition, meta-cognition, motivation, affects, and volition (Efklides 2009), are used by learners intuitively without understanding the conceptual background. Apart from supporting SRL in PLE creation and use through respective recommenders, collaboration tools and best practice sharing, ROLE raises awareness through a number of dedicated learning resources. These range from short videos explaining the SRL principles (see for example http:// youtu.be/jTa1vOH6JjA), to bespoke online courses about SRL that help teachers and students understand the mechanics and benefits behind SRL, such as the ones introduced in the previous section of this chapter. 


\section{The ROLE Case Studies and Test Beds}

The ROLE innovations in technology and methodology have been proven successful in a number of case studies that investigate the impact of PLEs on different forms of learning. Each case study has employed large test beds that have run continuously throughout the lifetime of the project and beyond (Mikroyannidis and Connolly 2012, 2013). The ROLE test beds cover a wide variety of rich contexts inside and outside of Europe, in which there is potential for significant impacts on both personalised and SRL. Each test bed concentrates on researching a large sample of representative individuals; this has enabled ROLE as a whole to collect experiences covering a large variety of learning contexts and requirements. The ROLE case studies and test beds are presented in detail in subsequent chapters of this book. A brief overview is provided below:

Case Study 1: Using Widget Bundles for Formal Learning in Higher Education-This case study explores the usefulness of the PLE for facilitating and complementing the learning that happens inside the classroom in Higher Education. The test beds of this case study are three universities: the RWTH Aachen University (RWTH) in Germany, the Shanghai Jiao Tong University (SJTU) in China and the University of Uppsala in Sweden. These test beds present a variety of learning cultures, different profiles of students, as well as different methods of teaching and learning, e.g. synchronous versus distant learning. Bespoke widget bundles were developed by the ROLE project in order to address the learning contexts and requirements of these test beds. These widget bundles were employed in different learning domains to support different types of learning in these test beds and were evaluated by both the teachers and the students.

Case Study 2: Designing PLE for Higher Education-In this case study, the potential benefits associated with enabling teachers and students to design, build, and use their PLEs collaboratively are investigated. The test beds of this case study are the Tongji University in China and three Swiss universities, namely the University of Fribourg, the University of Geneva, and the EPFL. In these test beds, a Web 2.0 platform enabling the construction, the sharing, and the repurposing of PLEs has been introduced. Participatory design and validation activities have been carried out in the framework of Higher Education, aiming at understanding the benefits of PLEs in academic institutions.

Case Study 3: Exploring OER for Informal Learning-This case study concerns the learner's potential transition from formal to informal learning. The test bed of this case study is OpenLearn, ${ }^{6}$ an OER repository offered by the Open University in the UK. OpenLearn users are primarily informal learners, who want to find and study OER either individually or in collaboration with others. The ROLE intervention in the OpenLearn test bed has been about improving the informal learning experience in a number of ways. First of all, by enabling individuals to build and personalise their learning environment, thus gaining more control over the use and

\footnotetext{
${ }^{6} \mathrm{http}: / /$ www.open.edu/openlearn
} 
manipulation of study materials. Additionally, the adoption of certain ROLE tools inside OpenLearn is offering further value to learners through fostering learning communities. This presents an opportunity to individual informal learners to be part of a shared learning experience instead of a lone study.

Case Study 4: Technology Enhanced Workplace Learning: Learning in the workplace is targeted by this case study, which explores the challenges and opportunities associated with SRL in the workplace and the sharing of best practices among employees. The test bed in question is Festo Lernzentrum Saar GmbH in Germany. Festo has experimented with the notion of the Personal Learning Management System (PLMS), a crossover between the PLE and the LMS. The PLMS aggregates learning resources and applications available in the web and selected by the learner. It facilitates learners in planning their learning activities, searching for learning content and tools, training and testing, as well as in reflecting and evaluating their learning progress.

The evaluation results from the ROLE test beds are presented in detail in the chapters of this book that discuss each case study. Overall, the evaluation results indicate the best suitability of the ROLE approach for self-regulated learners while providing significant improvements even in traditional learning scenarios where ROLE tools are used for homework-like assignments. Additionally, the successful evaluation of the ROLE approach has led partners to include it in their commercial products and consulting practices.

\section{PLEs for Inquiry-Based Learning: The weSPOT Project}

The ROLE project has been a pioneering initiative in PLE research. It has paved the way for more national and international research initiatives that explore the potential applications and benefits of PLEs in different learning contexts. Both the theoretical and technological frameworks developed by ROLE have been taken upon and extended by recent research projects. A prominent example of such an initiative is the weSPOT project, which is investigating the potential impact of PLEs in Inquiry-Based Learning.

Inquiry-based learning (IBL) enables learners to take the role of an explorer and a scientist as they try to solve issues they came across and that made them wonder, thus tapping into their personal feelings of curiosity. IBL leads to structured knowledge about a domain and to more skills and competences about how to carry out efficient and communicable research.

The European project weSPOT ${ }^{7}$ adopts a PLE-based approach in order to support learners and educators in IBL (Mikroyannidis et al. 2013c). The project focuses on IBL with a theoretically sound and technology-supported personal inquiry approach. weSPOT supports the meaningful contextualisation of scientific

\footnotetext{
${ }^{7}$ http://wespot.net
} 
concepts by relating them to personal curiosity, experiences, and reasoning. weSPOT addresses several challenges in the area of science education and technology support for building personal conceptual knowledge (Mikroyannidis et al. 2013b).

These principles have driven the development of the weSPOT inquiry space, ${ }^{8}$ a personal and social IBL environment that reuses and extends the Elgg open-source social networking framework. ${ }^{9}$ The weSPOT inquiry space has been built based on the following requirements (Mikroyannidis 2014):

- A widget-based architecture enables the personalisation of the inquiry environment, allowing teachers and students to build their inquiries out of mashups of inquiry components.

- Students can connect with their peers and form groups in order to build, share, and perform inquiries collaboratively.

Inquiries in the weSPOT inquiry space are consistent with the weSPOT pedagogical IBL model (Protopsaltis 2013). According to this model, an inquiry consists of the following six phases: (1) question/hypothesis, (2) operationalisation, (3) data collection, (4) data analysis, (5) interpretation/discussion, and (6) communication.

The weSPOT inquiry space enables its users (teachers and students) to create mashups of their preferred inquiry components, assign them to different phases of an inquiry, share them with other users, and use them collaboratively in order to carry out an inquiry. When creating a new inquiry, users are provided with a set of recommended inquiry components for each phase of the inquiry. They can then customise these sets of components by adding, removing, and arranging inquiry components for each phase of the inquiry.

The weSPOT inquiry space offers a variety of inquiry components to teachers and students, enabling them to create, edit, and share hypotheses, questions, answers, notes, reflections, mind maps, etc. Some of these components communicate with the APIs of REST web services offered by external tools. One of these external tools is the ARLearn mobile app, ${ }^{10}$ which allows students to collect different types of data (photos, videos, measurements, etc.) with their smartphones and share them with other inquiry members via the weSPOT inquiry space. A Learning Analytics dashboard visualises all the activities taking place within an inquiry, enabling teachers to monitor the progress of their students and students to self-monitor their progress.

Figure 5 shows an example mashup of inquiry components for a particular phase of an inquiry that explores the everyday uses of batteries. The phase is labelled "Discuss the findings" and corresponds to the "Interpretation/Discussion" phase of the weSPOT IBL model. In this phase, the members of the inquiry use collaboratively three inquiry components in order to discuss and interpret their findings.

\footnotetext{
${ }^{8}$ http://inquiry.wespot.net

${ }^{9}$ http://elgg.org

${ }^{10} \mathrm{http}: / /$ portal.ou.nl/en/web/arlearn
} 


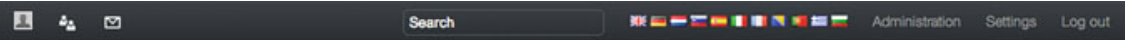

\section{Wesp inquiry Home Inquiries Activity Members $>$ More}

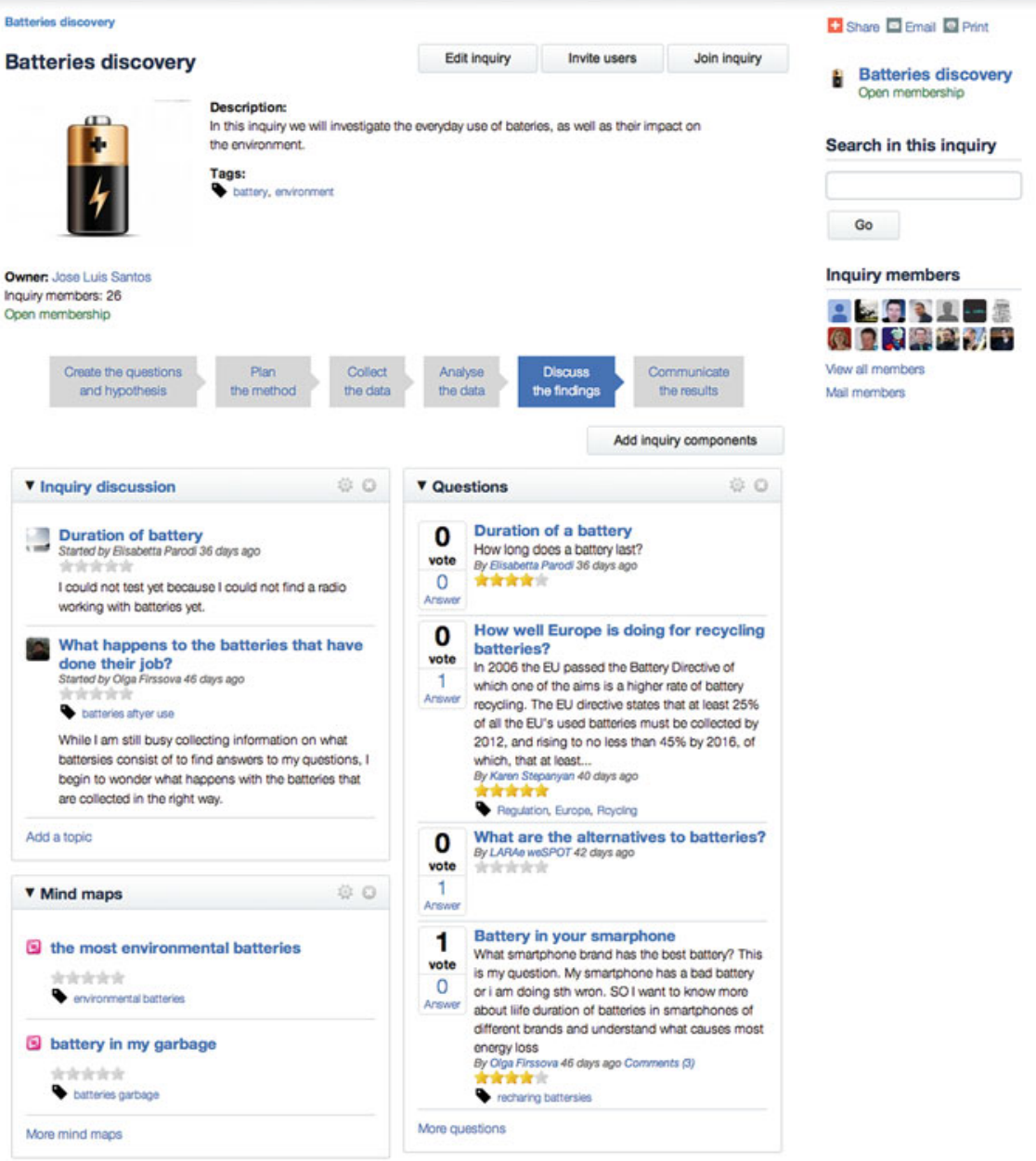

Cogyight 02014 weSPOT | Theme by Elggzone | Powerod by Bgg

Fig. 5 A mashup of inquiry components for discussing and interpreting the findings of an inquiry

They use the "Inquiry discussion" component to exchange their views asynchronously in discussion forums. They also use the "Questions" component in order to provide answers to the key research questions of this inquiry and vote for the best answers. Finally, they create and share mind maps containing interpretations of their findings via the "Mind maps" component. 
Additionally, users have access to external resources and widgets and can use them in their mashups together with the inquiry components offered by the weSPOT inquiry space. These resources and widgets originate from external LMSs, such as Moodle or Blackboard, or from external repositories of widgets, such as the one offered by the European project Go-Lab. ${ }^{11}$ In order to integrate external resources originating from LMSs, we have implemented the IMS Learning Tools Interoperability (LTI) specification, ${ }^{12}$ thus allowing teachers to include in their inquiries either course components from LMSs, such as discussion forums or quizzes, or entire LMS courses.

\section{Conclusions and Book Overview}

In summary, the vision of the ROLE project has been to provide the necessary infrastructure and processes for any learner across the world to assemble their own PLE, while enabling the education provider to exercise the necessary control to facilitate the certification of the learning achievements. From a technical point of view, the approach taken by ROLE enables the flexible composition of technologies by the end user in the sense of mashing-up learning tools and technologies at the "clients" side.

Today's rapidly changing education and employment conditions demand a lifelong learner who is flexible, motivated, and in control of his or her learning. The ROLE initiative has significantly advanced the state of the art in technologyenhanced learning, by providing lifelong learners with the tools and support they need for personalising their learning and developing a wide range of SRL skills.

The rest of this book presents in detail the theoretical and technological advances of the ROLE project, with particular emphasis on the applications of these advances in the case studies investigated by the project, as well as the evaluation results obtained by the project's test beds. More specifically, Chap. 2 introduces the SRL approach of the project, consisting of a formal framework that describes the SRL process, related competences, and guidelines. Additionally, the methods offered by the ROLE SRL framework on supporting learners in order to learn in a selfregulated way are presented.

Chapter 3 presents the evaluation framework and methodology of the project. The ROLE evaluation framework is case study-based and follows a multi-method approach. It integrates technological, organisational, psycho-pedagogical, and social aspects. At the same time, it provides a flexible and adaptive methodology, capable of accommodating the changes that are inevitable in the emerging field of personalised and SRL.

\footnotetext{
${ }^{11}$ http://www.golabz.eu/apps

${ }^{12} \mathrm{http}: / / \mathrm{www}$. imsglobal.org/lti/index.html
} 
Chapters 4-7 present the project's case studies and the test beds employed in each case study. As mentioned earlier in this chapter, the ROLE case studies and test beds cover a wide variety of learning contexts, ranging from formal to informal learning and from higher education to distance learning and workplace learning. Each test bed is presented according to its specific learning scenarios and requirements, the stakeholders involved, as well as the PLE intervention achieved by the project and the evaluation results.

Finally, Chap. 8 discusses the lessons learned from the development of the project's PLE framework. In particular, the overall architecture and its components, as well as the platforms in which the ROLE technological framework has been integrated are presented. In addition, the experiences and lessons learned from the design and development of the ROLE technological framework are discussed, together with the lessons learned from the collaboration both internally within the ROLE development team and externally with other open-source projects.

Acknowledgement The research leading to these results has received funding from the European Community's Seventh Framework Programme (FP7/2007-2013) under grant agreement no. 231396 (ROLE project) and under grant agreement no. 318499 (weSPOT project).

Open Access This chapter is distributed under the terms of the Creative Commons Attribution Noncommercial License, which permits any noncommercial use, distribution, and reproduction in any medium, provided the original author(s) and source are credited.

\section{References}

Abel RJ. Best practices in open source in higher education study: the state of open source software; 2006. Lake Mary: The Alliance for Higher Education Competitiveness. http://www.methodist. edu/csc/ossresearch/applications_vendors/OSS\%20Report.pdf

Atkins DE, Brown JS, Hammond AL. A review of the open educational resources (OER) movement: achievements, challenges, and new opportunities. Menlo Park: The William and Flora Hewlett Foundation. 2007. http://www.hewlett.org/uploads/files/Hewlett_OER_report. pdf

Bri D, Garcia M, Coll H, Lloret J. A study of virtual learning environments. WSEAS Trans Adv Eng Edu. 2009;1(6):33-43.

Chatti MA, Jarke M, Frosch-Wilke D. The future of e-learning: a shift to knowledge networking and social software. Int J Knowl Learn. 2007;3(4/5):404-20.

Dahrendorf D. Service syndication platform. ROLE project deliverable; 2013. http://www.roleproject.eu/wp-content/uploads-role/2009/02/role-deliverable-4.2-updatedM48.pdf

Efklides A. The role of metacognitive experiences in the learning process. Psicothema. 2009;21:76-82.

Fruhmann K, Nussbaumer A, Albert D. A psycho-pedagogical framework for self-regulated learning in a responsive open learning environment. In: International conference eLearning Baltics Science (eLBa Science 2010), Rostock, Germany; 2010.

Govaerts S, Helou SE, Duval E, Gillet D. A federated search and social recommendation widget. In: 2nd International workshop on social recommender systems (SRS 2011) in conjunction with the 2011 ACM Conference on Computer Supported Cooperative Work (CSCW 2011), Hangzhou, China; 2011. p. 1-8. 
Isaksson E. Personal learning service bundles. In: ROLE project deliverable. 2013. http://www. role-project.eu/wp-content/uploads-role/2009/02/role-deliverable-4.1-updatedM48.pdf

Mell P, Grance T. The NIST definition of cloud computing (draft). NIST Spl Publ. 2011;800:145.

Mikroyannidis A. The weSPOT inquiry space: a personal and social environment for inquirybased learning. In: 9th European Conference on Technology-Enhanced Learning (ECTEL). Graz, Austria; 2014.

Mikroyannidis A, Connolly T. Best-practice roadmap for ROLE implementation. ROLE project deliverable. 2012. http://www.role-project.eu/wp-content/uploads-role/2009/02/role-deliver able-5.5.pdf

Mikroyannidis A, Connolly T. Test bed evaluation report. In: ROLE project deliverable. 2013. http://www.role-project.eu/wp-content/uploads-role/2009/02/role-deliverable-5.4.pdf

Mikroyannidis A, Connolly T, Berthold M. Self regulated learning: iPad edition. 2013a. http://bit. ly/self-regulated-learning. The Open University.

Mikroyannidis A, Okada A, Scott P, Rusman E, Specht M, Stefanov K, Boytchev P, Protopsaltis A, Held P, Hetzner S, Kikis-Papadakis K, Chaimala F. weSPOT: a personal and social approach to inquiry-based learning. J Univers Comput Sci. 2013b;19(14):2093-111.

Mikroyannidis A, Okada A, Scott P. Personal learning environments for inquiry-based learning. Berlin, Germany: PLE Conference; 2013c.

Protopsaltis A, Hetzner S, Held P, Seitlinger P, Bedek M, Kopeinik S, Rusman E, Firssova O, Specht M, Haimala F, Kikis-Papadaki K, Okada A, Mikroyannidis A, Scott P. Pedagogical and Diagnostic Framework. In: weSPOT project deliverable. 2013. http://portal.ou.nl/documents/ 7822028/3b2c3110-98bf-4686-b2bd-5756fcab93f1

Steffens K. Self-regulated learning in technology-enhanced learning environments: lessons of a European peer review. Eur J Educ. 2006;41(3/4):353-79.

Van Harleman M. Personal learning environment. In: 6th IEEE International Conference on Advanced Learning Technologies (ICALT). IEEE Computer Society, Kerkrade, The Netherlands; 2006.

Vaquero LM, Rodero-Merino L, Caceres J, Lindner M. A break in the clouds: towards a cloud definition. ACM SIGCOMM Comput Commun Rev. 2008;39(1):50-5.

Wainwright K, Osterman M, Finnerman C, Hill B. Traversing the LMS terrain. In: Proceedings of the 35th annual ACM SIGUCCS fall conference, Orlando: ACM; 2007. p. 355-9.

Watson WR, Lee S, Reigeluth CM. Learning management systems: an overview and roadmap of the systemic application of computers to education. In: Neto FM, Brasileiro FV, editors. Advances in computer-supported learning. Hershey: Information Science; 2007.

Wilson S. Patterns of personal learning environments. Interact Learn Env. 2008;16(1):17-34.

Wilson S. Future VLE—-the visual version; 2005. http://www.cetis.ac.uk/members/scott/ blogview?entry $=20050125170206$

Zimmerman BJ. A social cognitive view of self-regulated academic learning. J Educ Psychol. 1989;81(3):329-39. 